\title{
Osteogenesis Imperfecta - An Overview
}

\author{
Akku Sara Jacob ${ }^{1}$, Dr J. Jananee ${ }^{2}$, Dr. Lakshmi Ravi ${ }^{3}$ \\ ${ }^{1}$ Student, Asan Memorial Dental College and Hospital, Chengalpattu \\ ${ }^{2}$ Reader, Dept of Oral Pathology, Asan Memorial Dental College and Hospital, Chengalpattu \\ ${ }^{3}$ Professor \& HOD Department of Orthodontics, Asan Memorial Dental College and Hospital, Chengalpattu
}

\begin{abstract}
Osteogenesis imperfecta (OI) is a congenital, generalized connective tissue disorder characterized by severe osteoporosis and bone fragility. Other features of the disease include dentinogenesis imperfecta, scoliosis, short stature, blue sclerae, hearing loss, and skin and ligament laxity
\end{abstract}

Keywords: Osteocytes Osteoblast, Blue Sclera

\section{Introduction}

Osteogenesis imperfecta (OI) is a congenital, generalized connective tissue disorder characterized by severe osteoporosis and bone fragility. Other features of the disease include dentinogenesis imperfecta, scoliosis, short stature, blue sclerae, hearing loss, and skin and ligament laxity ${ }^{1}$. Molecular defects in type I collagen genes, COL1A1 and COL1A2, were first associated with OI in the early 1980's'.

Osteogenesis imperfecta was classified several years ago into four types based on clinical, radiological and genetic features ${ }^{3}$.

variability in terms of number of fractures, even within the same family. Fractures typically begin when the children start to ambulate. Plain radiographs often are normal in appearance. These individuals may have blue sclera and hearing loss, although this may not occur before the second or third decade. Dentinogenesis imperfecta is not typically a major component of Type I. There may be subtle dental findings. There are no long-term studies to determine if the collagen defect might lead to later dental problems. Growth and stature are typically mildly decreased in type 1 OI.

Type II: Type II is historically described as perinatally lethal, typically from pulmonary failure related to the severe involvement of the chest cavity with small volume, deformity, and recurrent rib fractures. There may also be some involvement of the intrinsic collagen of the lung parenchyma ${ }^{4}$.These children are frequently diagnosed in prenatal ultrasounds with short, severely bowed long bones with multiple fractures. Radiographically, at the time of birth, they have severe bowing of the long bones, multiple fractures in different stages of healing, poorly defined cortices, and crumpling or wrinkling of the bones in an accordion-type fashion. There is poor tubulation with wide medullary canals. There is typically severe wedging deformity of the vertebrae. The skull is usually quite soft and large. Some of these children, including some treated with bisphosphonates, have survived for several years.

Type III: These patients are also frequently diagnosed on prenatal ultrasound. They also have relative shortening of the long bones, significant bowing, and multiple prenatal and postnatal fractures. These children continue to have fractures even with gentle handling. This is the most severe non-lethal form. They may have a very typical triangular facies, blue sclerae, dentinogenesis imperfecta, vertebral fractures, and frequently scoliosis. Without treatment with bisphosphonates, this OI type frequently demonstrates classic "popcorn epiphyses" of the long bones and patients have significant short stature.

Type IV: Traditionally, this classification has included children with phenotypes that did not fit into Sillence type I or III. These children typically have multiple fractures, varying degrees of deformity, as well as a great deal of variation in terms of color of the sclera, cranial settling, dentinogenesis imperfecta, and stature. With the recognition of recessive forms, many of these children previously classified as having type IV are now recognized as having one of these other, less common forms.

Type V: These individuals have increasing bone fragility and a moderately severe phenotype of OI. They also have calcification of the interosseous membrane which can be noted in the first year of life. This causes a significant decrease in pronation and supination. The radial head dislocates anteriorly, and long bone fracture can result in a very hypertrophic callus. There can be a radio-dense band at the end of the metaphysis. There is a unique mesh-like pattern of lamination histologically under polarizing light.

\section{Histopathological Features}

It is composed of immature spongy bone with trabeculae of cancellous bone are delicate and often shows mild fractures. Osteoblastic activity appears retarded and imperfect.

\section{Management and Treatment}

OI have not only recurrent fractures and severe bowing deformities, but also lax joints and connective tissue associated problems. Long-term, individuals may develop other significant health issues, including cardiac, pulmonary, and joint problems. Management consists of physiotherapy, rehabilitation and orthopaedic surgery. 


\section{International Journal of Science and Research (IJSR) \\ ISSN (Online): 2319-7064}

Index Copernicus Value (2013): 6.14 | Impact Factor (2014): 5.611

\section{Discussion}

Osteogenesis imperfect also known as brittle bone disorder exhibits fragile bones leading to multiple fractures during day today life. Other features include blue sclera, hypoplasia of teeth, impacted teeth, dirty pink tooth, bowing of limbs, deafness and peculiar shape of skull. Some bone diseases is till a myth, OI is one such disease which had to be identified in early childhood and proper management and treatment has to be taken throughout the life span

\section{References}

[1] Cheung and Glorieux, 2008; Rauch and Glorieux, 2004).

[2] Chu et al., 1983).

[3] Sillence, 1988; Sillence et al., 1979).

[4] Forlino et al., 2011; Sillence et al., 1979)

[5] Agarwal, V., and Joseph, B. (2005). Non-union in osteogenesis imperfecta. Journal of pediatric orthopaedics Part B / European Paediatric Orthopaedic Society, Pediatric Orthopaedic Society of North America 14, 451-455

[6] Alanay, Y., Avaygan, H., Camacho, N., Utine, G.E., Boduroglu, K., Aktas, D., Alikasifoglu, M., Tuncbilek, E., Orhan, D., Bakar, F.T., et al. (2010).

[7] Arundel, P., Offiah, A., and Bishop, N.J. (2011). Evolution of the radiographic appearance of the metaphyses over the first year of life in type $\mathrm{V}$ osteogenesis imperfecta: clues to pathogenesis.

[8] Breindl, M., Harbers, K., and Jaenisch, R. (1984). Retrovirus-induced lethal mutation in collagen I gene of mice is associated with an altered chromatin structure. Cell 38, 916.

[9] Breslau-Siderius, E.J., Engelbert, R.H., Pals, G., and van der Sluijs, J.A. (1998). Bruck syndrome: a rare combination of bone fragility and multiple congenital joint contractures. Journal of pediatric orthopaedics 7 , 35-38. Brude, E. (1986)

[10] Glorieux, F.H., Ward, L.M., Rauch, F., Lalic, L., Roughley, P.J., and Travers, R. (2002). Osteogenesis imperfecta type VI: a form of brittle bone disease with a mineralization defect.

[11] Pediatr Orthop 31, 655-660. Homan, E.P., Rauch, F., Grafe, I., Lietman, C., Doll, J.A., Dawson, B., Bertin, T., Napierala, D., Morello, R., Gibbs, R., et al. (2011). Mutations in SERPINF1 cause Osteogenesis imperfecta Type VI. Journal of bone and mineral research : the official journal of the American Society for Bone and Mineral Research.

[12] The Journal of clinical investigation 91, 709-716. Pizones, J., Plotkin, H., Parra-Garcia, J.I., Alvarez, P., Gutierrez, P., Bueno, A., and Fernandez-Arroyo, A. (2005). Bone healing in children with osteogenesis imperfecta treated with bisphosphonates. J Pediatr Orthop 25, 332-335. Plotkin, H. (2004). Syndromes with congenital brittle bones.

[13] Willing, M.C., Pruchno, C.J., Atkinson, M., and Byers, P.H. (1992). Osteogenesis imperfecta type $I$ is commonly due to a COL1A1 null allele of type I collagen. American journal of human genetics 51, 508515. Yao, Q., Li, M., Yang, H., Chai, H., Fisher, W., and Chen, C. (2005). Roles of cyclophilins in cancers and other organ systems. World journal of surgery 29, 276-280. 